\title{
TINJAUAN PENGAMAN GARDU DISTRIBUSI 37A TERHADAP LEDAKAN TRAFO DI SKIP DALAM PALDAM
}

\author{
Denny R. Pattiapon ${ }^{1)}$, J. J. Rikumahu ${ }^{2)}$ \\ ${ }^{1,2)}$ Teknik Elektro, Politeknik Negeri Ambon \\ redgiecilia@gmail.com
}

\begin{abstract}
Electrical power from Perusahaan Listrik Negara (PLN) is distribute to load use distribution transformer. Electrical power that distribute to load with distribution substation often causes fault on transformer. Based on the experience, fault on transformer can caused by several factors such as unstable power transformer, load unbalance, overload of transformer, less maintenance of transformers equipment, or other problems at the load side. From the result of the analysis, should be emphasized the load to balance and maintane the equipment of transformers to improve continuity of power supply for customers. There are some types of breaker at transformer is used for certain condition. Grounding on distribution substation purpose to secure the transformer and its conductive parts from touch voltage. Installation of distribution substation panel should be appropriate in order to secure for people.
\end{abstract}

\begin{abstract}
ABSTRAK
Daya listrik yang dewasa ini digunakan bersumber dari Perusahaan Listrik Negara (PLN), selanjutnya daya listrik tersebut didistribusikan ke pusat-pusat beban melalui transformator distribusi. Sistem pendistribusian energi listrik ke pusat beban melalui gardu distribusi sering kali menyebabkan terjadinya gangguan pada transformator distribusi. Berdasarkan pengalaman yang sering terjadi di lapangan dimana terjadi permasalahan pada trafo disebabkan oleh beberapa faktor diantaranya trafo daya tidak stabil, beban tidak seimbang, pembebanan yang melebihi kapasitas trafo dan masalah lain yang sering terjadi pada pusat-pusat beban, serta kurang terpeliharanya peralatan-peralatan transformator distribusi. Dari hasil analisis perlu ditekankan dalam menjaga keseimbangan beban serta pemeliharaan peratatan gardu distribusi demi meningkatkan pelayanan yang aman dan baik bagi konsumen. Sebuah transformator memiliki berbagai jenis pengaman yang digunakan untuk masing-masing kondisi serta waktu tertentu. Pembumian pada gardu distribusi bertujuan untuk mengamankan trafo serta bagian-bagian dari peralatan yang konduktif dari bahaya tegangan sentuh. Penyusunan peralatan pada panel gardu harus diatur sedemikian rupa sehingga aman bagi manusia.
\end{abstract}

Kata Kunci : Pengaman Gardu; Trafo Distribusi

\section{PENDAHULUAN}

Daya listrik yang dewasa ini digunakan bersumber dari Perusahaan Listrik Negara (PLN), selanjutnya daya listrik tersebut didistribusikan ke pusat-pusat beban melalui transformator distribusi. Sistem pendistribusian energi listrik ke pusat beban melalui gardu distribusi sering kali menyebabkan terjadinya gangguan pada transformator distribusi. Berdasarkan pengalaman yang sering terjadi di lapangan dimana terjadi permasalahan pada trafo disebabkan oleh beberapa faktor diantaranya trafo daya tidak stabil, beban tidak seimbang, pembebanan yang melebihi kapasitas trafo dan masalah lain yang sering terjadi pada pusat-pusat beban, serta kurang terpeliharanya peralatan-peralatan transformator distribusi.

Untuk menganalisa permasalahan yang terjadi pada sistem distribusi serta pemeliharaannya dan dapat menganalisa gangguan yang terjadi akibat pembebanan yang melebihi kapasitas transformator serta pemeliharaan pada peralatan-peralatan transformator distribusi.

\section{TINJAUAN PUSTAKA}

2.1 Pengaman Transformator

Pengaman Transformator adalah suatu cara yang digunakan untuk mencegah atau membatasi kerusakan peralatan terhadap gangguan sehingga kelangsungan penyaluran dapat dipertahankan.

Secara umum pengaman transformator dapat digolongkan dalam 2 kelompok jenis pengaman, yaitu:

1.Pengaman Obyek, yaitu sistem pengaman transformator terhadap gangguan yang terjadi di dalam transformator itu sendiri.

2. Pengaman Sistem, yaitu pengaman transformator terhadap gangguan yang terjadi dalam sistem tenaga listrik yang terjadi diluar transformator.

Adapun gangguan-gangguan yang sering dijumpai adalah :

1. Terjadinya arus lebih karena hubung singkat atau beban lebih.

2. Terjadinya arus hubung tanah.

3. Terjadinya gangguan di dalam transformator.

4. Terjadinya gangguan disebabkan sambaran petir

Untuk transformator distribusi dengan daya kecil biasanya untuk mengamankan arus hubung singkat digunakan sekring saja. Pengaman lebih lengkap akan menjadi terlampau mahal padahal daya terpasang 
tidak terlalu besar.

\subsection{Pengaman Arus}

Pengaman arus yang melindungi transformator umumnya peka terhadap perubahan-perubahan yang terjadi pada arus listrik yang mengalir.

\section{Pengaman Arus Lebih}

Pada alat pengaman arus lebih terdapat kepekaan terhadap besar arus yang mengalir, atau mendeteksi besaran arus yang melalui suatu jaringan dengan bantuan trafo arus. Alat-alat pengaman arus lebih dapat dibedakan menurut karakteristik arus waktu, berupa :

a) Relay arus waktu (Instantaneous relay) yaitu : relay yang bekerja seketika (tanpa waktu tunda) ketika arus yang mengalir melewati nilai settingnya, relay akan bekerja beberapa waktu mili detik (10 - 20 ms), ditunjukkan pada Gambar 1.
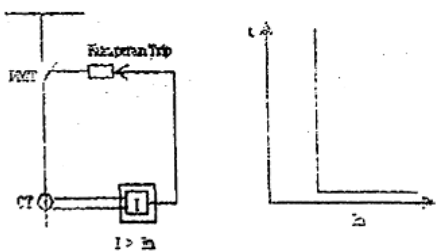

\section{Gambar 1. Karakteristik Waktu Seketika}

b) Relay arus lebih waktu tertentu (Defenite time relay) yaitu : relay ini akan memberikan perintah pada PMT pada saat terjadi gangguan hubung singkat dan besarnya arus gangguan melampaui settingnya $\left(\mathrm{I}_{\mathrm{s}}\right)$, dan jangka waktu kerja relay diperpanjang mulai pick up sampai kerja relay diperpanjang dengan waktu tertentu tidak tergantung besarnya arus yang mengerjakan relay, ditunjukkan pada Gambar 2.
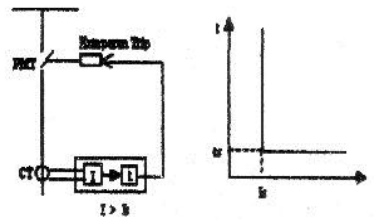

\section{Gambar 2. Karakteristik Relay Waktu Defenite}

c) Relay arus lebih waktu terbalik yaitu : relay yang akan bekerja dengan waktu tunda yang tergantung dan besarnya arus secara terbalik (Inverse time), makin besar arus makin kecil waktu tundahnya. Karakteristiknya dibedakan dalam tiga kelompok yaitu : standar invers, very invers, extreemely invers, ditunjukkan pada Gambar 3.
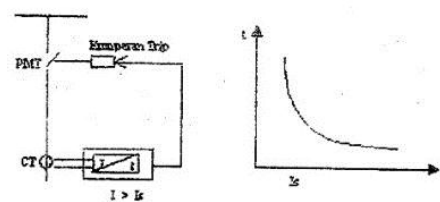

c)

Gambar 3. Karakteristik Relay Waktu Terbalik

Cara kerja relay arus lebih :
Apabila tejadi gangguan arus lebih, baik pada tiap fasa maupun pada ketiga fasanya, maka terdapat aliran arus pada kumparan relay I, ditunjukkan pada Gambar 4.

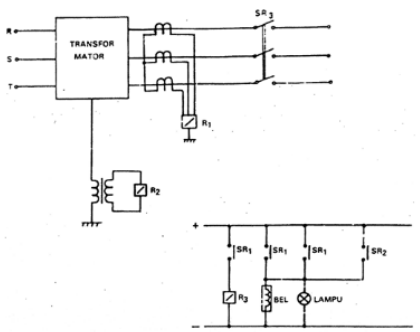

\section{Gambar 4. Rangkaian Pengaman Relay Arus Lebih}

1.Pengaman arus selisih, digunakan 2 buah transformator arus yang ditempatkan pada sisi primer maupun sisi sekunder dan pada kedua transformatorm itu dihubungkan dengan sebuah kumparan.

2.Sekering (fuse) adalah pengaman lebur yang fungsinya mengamankan peralatan listrik dari gangguan hubung singkat. Dalam pemasangannya, sekring dihubungkan seri pada masing-masing hantaran phasa yang tidak di ketanakan $(\mathrm{R}, \mathrm{S}, \mathrm{T})$. berdasarkan bentuknya sekring dapat di klasifikasikan menurut tipe atau jenisnya di antaranya tipe ulir, tipe tabung, dan tipe pisau.

a) Tipe Ulir terdiri dari sebuah silinder porselin, di dalamnya terdapat selain kawat perak (smeldreed), juga sebuah kawat tahanan. Ujung kawat itu di soldir pada kontak bawah dan kontak atas pengaman fuse.

b) Tipe Tabung, pengaman lebur dengan kapasitas yang relatif mulai kapasitas pemutusan yang rendah hingga tinggi dan dapat dijumpai dalam rating tegangan extra rendah, tegangan rendah, tegangan menengah, ataupun tegangan tinggi, ditunjukkan pada Gambar 5.

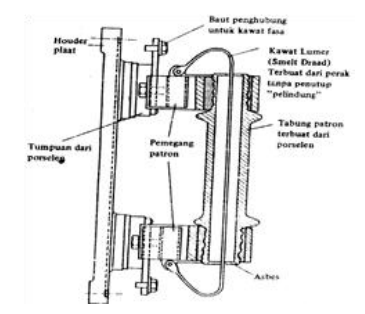

\section{Gambar 5. Suatu Potongan Penampang Pengaman Tipe Tabung}

c)Tipe Pisau sering disebut pula HRC (High Rupturing Capasity). Sekring tipe ini merupakan jenis sekring pengaman dengan kapasitas pemutusan tinggi, ditunjukkan pada Gambar 6 . 


\section{JURNAL SIMETRIK VOL 7, NO. 2, DESEMBER 2017}

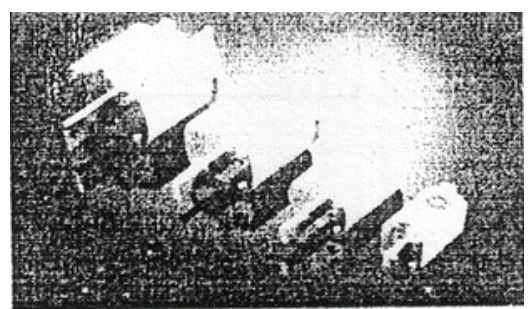

\section{Gambar 6. Pengaman Arus Tipe Pisau}

Untuk menentukan kemampuan hantar arus sebuah pengaman harus ditentukan arus yang dipakai berdasarkan daya beban yang dihubungkan, rumus yang digunakan :

1. Untuk arus bolak-balik fasa satu :

$$
I=\frac{P}{U \cos \varphi}
$$

2. Untuk arus bolak-balik fasa tiga :

$$
I=\frac{P}{U \cos \varphi \sqrt{3}}
$$

Untuk tegangan bolak-balik fasa satu, U adalah tegangan fasanya, umumnya $220 \mathrm{~V}$. Untuk tegangan fasa tiga, $U$ adalah tegangan antar fasanya umumnya $380 \mathrm{~V}$. Cara untuk menentukan pengaman utama yang diperlukan adalah

$$
\mathrm{I}_{\mathrm{n}}=\mathrm{I}_{\mathrm{t}} \mathrm{x} \text { a }
$$

Dimana :

$\mathrm{I}_{\mathrm{n}}=$ Ditentukan berdasarkan arus yang dipakai

$\mathrm{I}_{\mathrm{t}}=$ Jumlah arus yang dipakai, dihitung dari daya beban seluruhnya

$\mathrm{a}=$ Faktor keserempakan

3. Pelebur (fuse cut out) adalah suatu alat pemutus, dimana dengan meleburnya bagian dari komponen yang telah dirancang khusus dan disesuaikan ukurannya untuk membuka rangkaian dimana pelebur tersebut dipasang dan memutuskan arus bila arus tersebut melebihi suatu nilai dalam waktu tertentu.

4. Pemutus Balik Otomatis (recioser) ini secara fisik mempunyai 'kemampuan seperti pemutus beban, yang dapat bekerja secara otomatis untuk mengamankan sistem dari arus lebih yang diakibatkan adanya gangguan hubung singkat.

5. Saklar Seksi Otomatis (Sectionaliser) adalah alat perlindungan terhadap arus lebih, hanya dipasang bersama-sama dengan PBO yang berfungsi sebagai pengaman back-upnya.

\subsection{Pengaman Buchholz}

Relay Buchholz banyak dipergunakan pada transformator minyak dan pada umumnya kerusakankerusakan pada transformator minyak selalu didahului oleh timbulnya gas dalam transformator. Adapun gangguan-gangguan yang menyebabkan timbulnya gas transformator adalah gangguan pada sambungan, gangguan hubung tanah, gangguan hubung singkat, dan kerusakan minyak transformator.

\subsection{Pengaman Termal}

Dapat saja terjadi sebuah transformator mengalami beban lebih yang tidak begitu besar, ini tidak akan menyebabkan pengaman arus berfungsi. Tetapi beban lebih ini menyebabkan suhu transformator berangsur-angsur naik dan kenaikan ini dapat mengakibatkan kerusakan isolasi transformator. Untuk mencegah kemungkinan demikian sebuah transformator biasanya dilengkapi dengan sebuah thermometer yang dapat dibaca dari luar. Cara pengaman suhu dengan alat ukur panas saja tidak cukup bagi transformator yang besar dan penting apalagi bila gardu tidak dijaga.

\subsection{Pembumian}

Pembumian disini diartikan penyambungan rangka peralatan ke tanah.. Adapun pembumian di Gardu transformator dapat dilakukan dengan berbagai sistem yaitu :

1. Sistem Pembumian Gabungan

Sistem pembumian untuk Gardu dengan dua atau lebih kabel tegangan tinggi pada arah yang berlawanan serta panjang lebih $3 \mathrm{~km}$ atau Gardu dengan kabel berselubung logam (Timah atau alumunium) yang tidak mengisolasi atau Gardu dengan sisi tegangan hantaran udara.

2. Sistem Pembumian Gardu Dengan Hantaran SUTM Sistem pembumian ini dilakukan apabila Gardu yang terhubung kawat jaringan udara tegangan tinggi dan kabel-kabel tegangan rendah berpelindung logam dimana pemisahan pembumian sistem tegangan tinggi dan sistem pembumian tegangan rendah sulit dilakukan.

3. Sistem Pembumian Terpisah

Sistem pembumian ini apabila pembumian tegangan tinggi dan sistem pembumian tegangan rendah dipisahkan, atau jika sistem pembumian.

4. Gabungan Sistem Pembumian

Sistem gabungan ini juga diantara pembumian sistem tegangan tinggi dan sistem tegangan rendah sangat sulit.

5. Pembumian Titik Sentral

Pembumian titik sentral dari sistem akan menambah dalam pengaman dan kedayagunaan peralatan pengaman bila terjadi hubung pendek ke tanah pada sistem.

6. Pembumian Tegangan Rendah

Pembumian ini adalah pembumian rangkaian daya di setiap bagian sistem, komponen-komponen terdiri dari :

a) Penghantar Bumi yaitu penghantar utama yang menuju ke batang pembumian dan terhubung pada batang tersebut.

b) Batang Elektroda Pembumian ini berupa sebuah elektroda pita besi yang ditanamkan horizontal di tanah dan batang elektroda yang ditanam vertikal ke tanah, ditunjukkan pada Gambar 7 . 

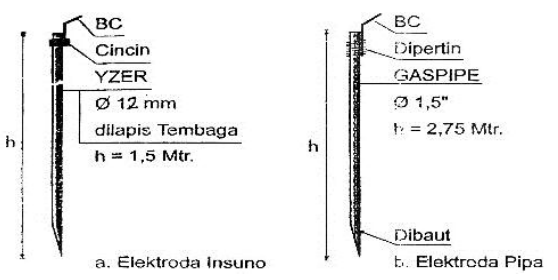

Gambar 7. Elektroda Bumi

\section{METODOLOGI}

3.1 Lokasi atau Objek Penelitian

Lokasi atau objek penelitian pada Gardu Distribusi 37A di Skip Dalam Paldam.

\subsection{Identitas Dan Pengukuran Variabel}

Variabel yang diamati adalah pembebanan yang melebihi kapasitas transformator distribusi.

Variabel yang dianalisa adalah keseimbangan beban Trafo yang meliputi pemeliharaan peralatan transformator distribusi.

\subsection{Sumber Data}

Sumber Data Primer diperoleh secara langsung pada PT. PLN (Persero) Cabang Ambon dengan mengadakan peninjauan pada Gardu Distribusi 37A di Skip Dalam Paldam.

\subsection{Teknik Pengambilan Data}

Adapun teknik pengambilan data yang digunakan oleh penulis adalah :

- Observasi : Penulis mengadakan pengamatan secara langsung pada lokasi penelitian.

- Kepustakaan : Menggunakan referensi dengan segala teori-teori yang ada hubungannya dengan penulisan ini.

\subsection{Alat Yang Digunakan}

Adapaun alat yang digunakan dalam tinjauan ini yaitu :

- Alat ukur tang Amper.

- Alat ukur multi meter.

\section{HASIL DAN PEMBAHASAN}

\subsection{Perlengkapan Komponen Pengaman Gardu} Distribusi 37A Di Skip Dalam Paldam

Setiap bagian perlengkapan pengaman peralatan gardu yang digunakan untuk penyaluran tenaga listrik harus mempunyai karakteristik yang sesuai dengan nilai dan kondisi, termasuk memperhatikan jenis, ukuran, tegangan dan kemampuannya,sehingga tidak mempengaruhi dan tidak menyebabkan efek merusak pada perlengkapan lain atau mengganggu suplai selama pelayanan normal. Spesifikasi peralatan gardu distribusi 37A yang digunakan untuk penyaluran tenaga listrik diantaranya :

a) Trafo 3 Fasa berkapasitas $200 \mathrm{KVA}$

- Tipe UNINDO.

- Daya 200 KVA.

- Tegangan Impedansi $4 \%$.

- Tegangan Primer $20 \mathrm{KV}$.
- Tegangan Sekunder380V.

- Frekuensi $50 \mathrm{~Hz}$

- Pendinginan Minyak Trafo.

b)Hekbom, sakelar utama pada gardu trafo distribusi, saklar ini merupakan jenis pemisah yang digunakan untuk memutus dan menghubung rangkaian listrik secara manual.

c) Rel (Pelat Tembaga), merupakan pelat tembaga yang di gunakan yang berfungsi sebagai rak pembagi tegangan, dan rel ini di letakan diatas isolator tumpu agar tidak bersentuhan dengan panel Gardu.

d) $\mathrm{NH}$ - Fuse, pada umumnya komponen pengaman jalur yang terdapat pada Gardu Distribusi Jaringan Tegangan Rendah (JTR) yaitu pelebur tegangan rendah, pelebur ini di pasang pada rak pembagi tegangan rendah di sisi sekunder trafo distribusi. Fungsi dari komponen ini adalah sebagai pengaman dari terjadinya hubungan singkat pada semua penyulang JTR dari layanan dari gardu distribusi tersebut.

\subsection{Analisa Beban}

Untuk mencegah atau membatasi kerusakan pada peralatan dalam penyaluran tenaga listrik perlu ditekankan agar menjaga keseimbangan beban berdasarkan hasil pengukuran beban puncak.

Ditunjukan pada Tabel 1, hasil pengukuran beban puncak pada Gardu Distribusi 37A di Skip Dalam Paldam.

\section{Tabel 1. Pengukuran Beban Dan Tegangan} Ujung Jaring Gardu Distribusi
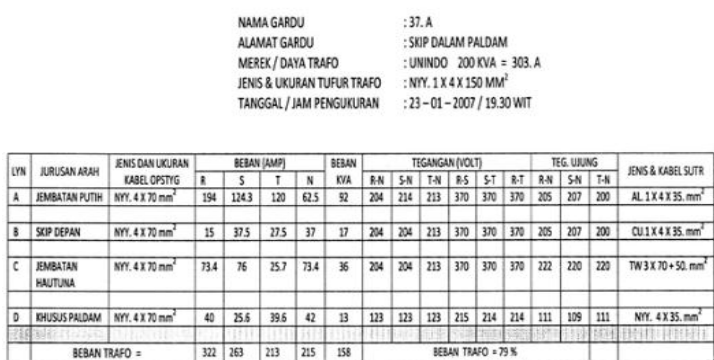

Total beban pada saat beban puncak untuk masingmasing fasa pada tiap jalur untuk Tabel 1 sebagai berikut :

- Total daya masing - masing fasa pada jalur $1 \mathrm{P}_{\mathrm{R} 1}$ daya pada fasa $R$

$\mathrm{P}_{\mathrm{R} 1}=\mathrm{V}_{\mathrm{R}}-\mathrm{N} . \mathrm{I}_{\mathrm{R} 1}$

$$
=204.194
$$$$
=39576 \mathrm{VA}
$$

$\mathrm{P}_{\mathrm{s} 1}$ daya total pada fasa $\mathrm{S}$

$$
\begin{aligned}
\mathrm{P}_{\mathrm{s} 1} & =\mathrm{V}_{\mathrm{s}}-\mathrm{N} . \mathrm{I}_{\mathrm{s} 1} \\
& =214.124,3 \\
& =26600,2 \mathrm{VA}
\end{aligned}
$$

$\mathrm{P}_{\mathrm{T} 1}$ daya total pada fasa $\mathrm{T}$

$\mathrm{P}_{\mathrm{T} 1}=\mathrm{V}_{\mathrm{T} 1}-\mathrm{N} \cdot \mathrm{I}_{\mathrm{T} 1}$

$$
=213.120
$$

$$
=25560 \mathrm{VA}
$$

- Total daya masing-masing fasa pada jalur 2 
$\mathrm{P}_{\mathrm{R} 2}$ daya pada fasa $\mathrm{R}$

$\mathrm{P}_{\mathrm{R} 2}=\mathrm{V}_{\mathrm{R}}-\mathrm{N} \cdot \mathrm{I}_{\mathrm{R} 2}$

$$
=204.15=3060 \mathrm{VA}
$$

$\mathrm{P}_{\mathrm{s} 2}$ daya total pada fasa $\mathrm{S}$

$\mathrm{P}_{\mathrm{s} 2}=\mathrm{V}_{\mathrm{s}}-\mathrm{N} . \mathrm{I}_{\mathrm{S} 2}$

$=204.37,5$

$=37,50 \mathrm{VA}$

$\mathrm{P}_{\mathrm{T} 2}$ daya total pada fasa $\mathrm{T}$

$\mathrm{P}_{\mathrm{T} 2}=\mathrm{V}_{\mathrm{T}}-\mathrm{N} \cdot \mathrm{I}_{\mathrm{T} 2}$

$=213.27,5$

$=5857,5 \mathrm{VA}$

- Total daya masing-masing fasa pada jalur 3

$\mathrm{P}_{\mathrm{R} 3}$ daya pada fasa $\mathrm{R}$

$$
\begin{aligned}
\mathrm{P}_{\mathrm{R} 3} & =\mathrm{V}_{\mathrm{R}}-\mathrm{N} \cdot \mathrm{I}_{\mathrm{R} 3} \\
& =204 \cdot 73,4 \\
& =14793,6 \mathrm{VA}
\end{aligned}
$$

$\mathrm{P}_{\mathrm{s} 3}$ daya total pada fasa $\mathrm{S}$

$\mathrm{P}_{\mathrm{s} 3}=\mathrm{V}_{\mathrm{s}}-\mathrm{N} . \mathrm{I}_{\mathrm{s} 3}$

$=204.76$

$=15504 \mathrm{VA}$

$\mathrm{P}_{\mathrm{T} 3}$ daya total pada fasa $\mathrm{T}$

$\mathrm{P}_{\mathrm{T} 3}=\mathrm{V}_{\mathrm{T}}-\mathrm{N} . \mathrm{I}_{\mathrm{T} 3}$

$$
=213.25,7
$$$$
=5474,1 \mathrm{VA}
$$

- Total daya masing-masing fasa pada jalur 4

$\mathrm{P}_{\mathrm{R} 4}$ daya total pada fasa $\mathrm{R}$

$$
\begin{aligned}
\mathrm{P}_{\mathrm{R} 4} & =\mathrm{V}_{\mathrm{R}}-\mathrm{N} . \mathrm{I}_{\mathrm{R} 4} \\
& =123.40 \\
& =4920 \mathrm{VA}
\end{aligned}
$$

$\mathrm{P}_{\mathrm{s} 4}$ daya total pada fasa $\mathrm{S}$

$\mathrm{P}_{\mathrm{s} 4}=\mathrm{V}_{\mathrm{s}}-\mathrm{N} . \mathrm{I}_{\mathrm{s} 4}$

$=123 \cdot 25,6$

$=3148,8 \mathrm{VA}$

$\mathrm{P}_{\mathrm{T} 4}$ daya total pada fasa $\mathrm{T}$

$\mathrm{P}_{\mathrm{T} 4}=\mathrm{V}_{\mathrm{T}}-\mathrm{N} \cdot \mathrm{I}_{\mathrm{T} 4}$

$=123.39,6$

$=4870,8 \mathrm{VA}$

Besar beban pada saat beban puncak untuk masing - masing fasa, ditunjukkan pada Tabel 2.

Tabel 2. Total Beban

\begin{tabular}{|l|l|l|l|}
\hline \multicolumn{4}{|c|}{ Total beban 3 fasa } \\
\hline \multicolumn{1}{|c|}{$\mathrm{R}$} & \multicolumn{1}{|c|}{$\mathrm{S}$} & \multicolumn{1}{c|}{ T } & \multicolumn{1}{c|}{ Jumlah } \\
\hline 62529,6 & 45290,5 & 41762,4 & 149582,5 \\
VA & VA & VA & VA \\
\hline
\end{tabular}

Dari Tabel 2, dapat diketahui pembebanan antara ketiga fasa mengalami ketidakseimbangan beban, hal ini diperoleh dari jauhnya total beban masing-masing fasa yang ditetapkan, karena selisih antara penggunaan beban ketiga fasa antara $R$ dengan fasa $S$ adalah 17239,1 VA dan antara fasa R dengan ketiga fasa mengalami ketidakseimbangan beban, hal ini diperoleh dari jauhnya total beban masing-masing fasa yang ditetapkan, karena selisih antara penggunaan beban ketiga fasa antara $\mathrm{R}$ dengan fasa $\mathrm{S}$ adalah 17239,1 VA dan antara fasa $R$ dengan fasa $T$ mencapai 20762,2 VA.

\section{Tabel 3. Pengukuran Beban Dan Tegangan Ujung Jaring Gardu Distribusi 37A Di Skip Dalam Paldam}

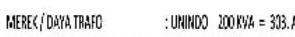

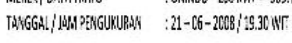

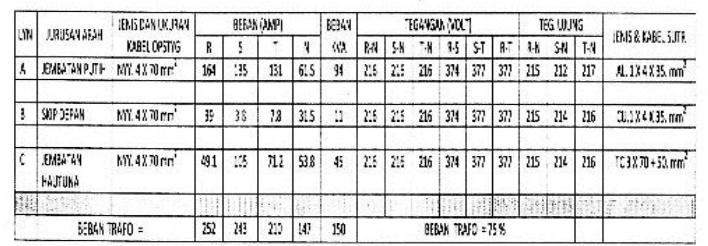

Dari hasil pengukuran beban pada Gardu 37A, ditunjukkan pada Tabel 3, dapat digunakan rumus hitung untuk menghitung beban fase setiap jalur dari masing-masing arus yang diukur dengan menggunakan persamaan $\mathrm{P}_{\mathrm{p}}=\mathrm{V}_{\mathrm{p}}$. I, yang dapat dilihat dari hasil analisa di bawah ini.

- Total daya masing-masing fasa pada jalur 1

$P_{R 1}$ daya total pada fasa $R$

$$
\begin{aligned}
\mathrm{P}_{\mathrm{R} 1} & =\mathrm{V}_{\mathrm{R}}-\mathrm{N} . \mathrm{I}_{\mathrm{R} 1} \\
& =216.164 \\
& =35.424 \mathrm{VA}
\end{aligned}
$$

$\mathrm{P}_{\mathrm{s} 1}$ daya pada fasa $\mathrm{S}$

$\mathrm{P}_{\mathrm{s} 1}=\mathrm{V}_{\mathrm{s}}-\mathrm{N} \cdot \mathrm{I}_{\mathrm{s} 1}$

$$
=216.135
$$

$$
=29.160 \mathrm{VA}
$$

$\mathrm{P}_{\mathrm{T} 1}$ daya pada fasa $\mathrm{T}$

$\mathrm{P}_{\mathrm{T} 1}=\mathrm{V}_{\mathrm{T}}-\mathrm{N} \cdot \mathrm{I}_{\mathrm{T} 1}$

$$
=216.39
$$

$=28.296 \mathrm{VA}$

- Total daya masing-masing fasa pada jalur 2

$P_{R 2}$ daya total pada fasa $R$

$$
\begin{aligned}
\mathrm{P}_{\mathrm{R} 2} & =\mathrm{V}_{\mathrm{R}}-\mathrm{N} . \mathrm{I}_{\mathrm{R} 2} \\
& =216.39 \\
& =8.424 \mathrm{VA}
\end{aligned}
$$

$\mathrm{P}_{\mathrm{s} 2}$ daya pada fasa $\mathrm{S}$

$\mathrm{P}_{\mathrm{s} 2}=\mathrm{V}_{\mathrm{s}}-\mathrm{N} . \mathrm{I}_{\mathrm{s} 2}$

$$
=216 \cdot 3,8
$$

$$
=820,8 \mathrm{VA}
$$

$\mathrm{P}_{\mathrm{T} 2}$ daya pada fasa $\mathrm{T}$

$\mathrm{P}_{\mathrm{T} 2}=\mathrm{V}_{\mathrm{T}}-\mathrm{N} . \mathrm{I}_{\mathrm{T} 2}$

$$
=216.7,8
$$

$$
=1684,8 \mathrm{VA}
$$

- Total daya masing-masing fasa pada jalur 3

$\mathrm{P}_{\mathrm{R} 3}$ daya total pada fasa $\mathrm{R}$

$$
\begin{aligned}
\mathrm{P}_{\mathrm{R} 3} & =\mathrm{V}_{\mathrm{R}}-\mathrm{N} . \mathrm{I}_{\mathrm{R} 3} \\
& =216.49,1 \\
& =10605,6 \mathrm{VA}
\end{aligned}
$$

$\mathrm{P}_{\mathrm{s} 3}$ daya pada fasa $\mathrm{S}$

$\mathrm{P}_{\mathrm{s} 3}=\mathrm{V}_{\mathrm{s}}-\mathrm{N} . \mathrm{I}_{\mathrm{s} 3}$

$$
=216.105
$$$$
=22.680 \mathrm{VA}
$$

$\mathrm{P}_{\mathrm{T} 3}$ daya pada fasa $\mathrm{T}$

$\mathrm{P}_{\mathrm{T} 3}=\mathrm{V}_{\mathrm{T}}-\mathrm{N}$. $\mathrm{I}_{\mathrm{T} 3}$

$$
=216.71,2
$$

$=15379,2 \mathrm{VA}$ 
Besar beban pada saat beban puncak untuk masing-masing fase pada setiap jalur maka dapat diperoleh total beban keseluruhan pada tiga fase seperti yang ditunjukkan pada Tabel 4.

Tabel 4. Total Beban Tiga Fase

\begin{tabular}{|l|l|l|l|}
\hline \multicolumn{3}{|c|}{ TOTAL BEBAN 3 FASE } & JUMLAH \\
\cline { 1 - 3 } $\mathrm{R}$ & $\mathrm{S}$ & $\mathrm{T}$ & \multirow{2}{*}{$152.474,4$} \\
\cline { 1 - 2 } $54.453,6$ & $52.660,8$ & 45.360 & VA \\
VA & VA & VA & \\
\hline
\end{tabular}

- Perhitungan beban KVA trafo, ditunjukkan pada Tabel 5.

Kelompok A : $(165+135+131):(\sqrt{ } 3 \times 380 / 1000)$ $=94 \mathrm{KVA}$

Kelompok B : $(39+3,8+7,8):(\sqrt{ } 3 \times 380 / 1000)$ $=11 \mathrm{KVA}$

Kelompok C : $(49,1+105+71,2):(\sqrt{ } 3 \times 380 /$ 1000)

$=45 \mathrm{KVA}$

- Persen trafo $=\frac{\text { Kapasitas beban KVA }}{\text { Kapasitas trafo } \times 100}$

$$
\begin{aligned}
& =\frac{150}{200 \times 100} \\
& =75 \%
\end{aligned}
$$

Tabel 5. Total Beban KVA Trafo

\begin{tabular}{|l|c|c|}
\hline Layanan & Beban KVA & Beban Trafo \\
\hline Kelompok A & 94 & \multirow{2}{*}{$75 \%$} \\
\hline Kelompok B & 11 & \\
\hline Kelompok C & 45 & \\
\hline Jumlah & 150 & \\
\hline
\end{tabular}

- Perhitungan Kapasitas Pengaman

Kapasitas pengaman dihitung sebagai berikut :

Kelompok A :

$$
\frac{94 / 380}{\sqrt{3} \times 1000}=142,98 \mathrm{~A}
$$

Kelompok B :

$$
\frac{11 / 380}{\sqrt{3} \times 1000}=16,7 \mathrm{~A}
$$

Kelompok C :

$$
\frac{\mathrm{A}_{45 / 380}}{\sqrt{3} \times 1000}=68,4
$$

\subsection{Pemeliharaan Gardu Transformator}

Pemeliharaan transformator dibagi atas beberapa bagian yang dianggap penting dan sering terjadi gangguan di bagian - bagian tersebut, pembagian ini meliputi :

a) Bagian - bagian diluar tangki Transformator

Bagian terminal dan isolasi terminal merupakan bagian yang penting dan harus mendapatkan perhatian. Apabila terminal beserta isolasinya dalam keadaan kotor, dapat terjadi pelepasan tegangan dari suatu fasa ke tanah.

b)Kumparan Dari Inti Transformator Apabila pada kumparan atau pada inti transformator atau keduanya terdapat kotoran, dapat menyebabkan terjadinya beberapa macam gangguan.

Misalnya temperatur meningkat atau gangguan hubung singkat. Dengan adanya gangguan ini, tegangan akan menurun dan arus masuk bertambah besar. Ini berakibat selain terganggunya pelayanan beban juga dapat menyebabkan rusaknya transformator.

c) Minyak Pendingin Transformator

Pemeliharaan terhadap minyak pendingin transformator biasanya dilakukan dengan mengambil contoh minyak di dalam tangki dan diadakan pengujian kembali. Jika hasil pengujian baik, maka minyak tidak perlu diganti. Tetapi jika hasil jelek, maka minyak harus segera diganti dengan yang baru.

d)Alat - alat Pengaman

Alat pengaman harus dipelihara dengan baik. Maksudnya agar alat-alat pengaman dapat bekerja sesuai dengan fungsinya.

Pemeliharaan alat pengaman ini dengan menghindarkan alat tersebut dari debu, sebab debu dapat menghambat mekanisme kerja alat tersebut. Selain itu kontaktor - kontaktor harus dibersihkan dan kemudian diadakan pengujian kembali karakteristik alat - alat pengaman tersebut.

\section{PENUTUP}

\subsection{Kesimpulan}

Kesimpulan yang diambil adalah :

1). Dari hasil analisis perlu ditekankan dalam menjaga keseimbangan beban serta pemeliharaan peratatan gardu distribusi demi meningkatkan pelayanan yang aman dan baik bagi konsumen.

2). Sebuah transformator memiliki berbagai jenis pengaman yang digunakan untuk masing-masing kondisi serta waktu tertentu.

3). Pembumian pada gardu distribusi bertujuan untuk mengamankan trafo serta bagian-bagian dari peralatan yang konduktif dari bahaya tegangan sentuh.

4). Penyusunan peralatan pada panel gardu harus diatur sedemikian rupa sehingga rapi dan aman.

\subsection{Saran}

Dari beberapa kesimpulan disarankan bahwa :

1). Perlengkapan gardu harus dirancang sedemikian rupa sehingga dalam kerja normal tidak membahayakan atau merusak, dipasang secara baik dan harus tahan terhadap kerusakan mekanis, termal dan kimiawi.

2). Dalam perencanaan gardu distribusi harus disesuaikan dengan PUIL dan peraturanperaturan lain yang berlaku dilingkungan PLN.

3). Pentanahan pada gardu harus dilakukan secara baik agar terhindar dari bahaya akibat sambaran petir. Disamping itu, pentanahan yang baik akan 
lebih mengakitfkan relay - relay pemutus.

\section{DAFTAR PUSTAKA}

Agus Gunawan Wibisono Ir. Sukisno Ir, 1979, Petunjuk Praktek Industri, Jakarta.

Artono Aris Munandar. Prof. Dr, Teknik Tegangan Tinggi.

Hamzah Berhim, Drs, 1991, Pengantar Teknik Tenaga Listrik, Andi Offset, Yogyakarta.

Pabla A. S. Abdul Hadi Ir, 1989, Sistem Distribusi Daya Listrik.

P. Van. Marten, E. Setiawan Ir, 1983, Instalasi Listrik Arus Kuat 3, Penerbit CV. Trimitra Mandiri, Jakarta.

Suryatmo F, 2002, Teknik Listrik Instalasi Penerangan, Penerbit Rineka Cipta, Jakarta. 